\title{
Diabetic ketoacidosis at the onset of type 1 diabetes is associated with future $\mathrm{HbA}_{1 \mathrm{c}}$ levels
}

\author{
S. Fredheim • J. Johannesen - A. Johansen • L. Lyngsøe • \\ H. Rida - M. L. M. Andersen - M. H. Lauridsen - B. Hertz • \\ N. H. Birkebæk • B. Olsen - H. B. Mortensen - J. Svensson • \\ the Danish Society for Diabetes in Childhood and Adolescence
}

Received: 9 October 2012 / Accepted: 21 January 2013 /Published online: 7 February 2013

(C) Springer-Verlag Berlin Heidelberg 2013

\begin{abstract}
Aims/hypothesis We investigated the long-term impact of diabetic ketoacidosis (DKA) at onset on metabolic regulation and residual beta cell function in a Danish population with type 1 diabetes.

Methods The study is based on data from DanDiabKids, a Danish national diabetes register for children. The register provides clinical and biochemical data on patients with type 1 diabetes diagnosed in 1996-2009 and then followed-up
\end{abstract}

Electronic supplementary material The online version of this article (doi:10.1007/s00125-013-2850-z) contains per-reviewed but unedited supplementary material, which is available to authorised users.

S. Fredheim $(\bowtie) \cdot$ J. Johannesen $\cdot$ H. Rida $\cdot$ M. L. M. Andersen $•$

B. Olsen · H. B. Mortensen · J. Svensson

Department of Paediatrics, Herlev Hospital, Arkaden,

Turkisvej 14,

DK 2730 Herlev, Denmark

e-mail: sirifredheim@dadlnet.dk

S. Fredheim · J. Johannesen · H. B. Mortensen · J. Svensson

Faculty of Health and Medical Sciences,

University of Copenhagen, Copenhagen, Denmark

A. Johansen

Department of Paediatrics, Rigshospitalet, Copenhagen, Denmark

L. Lyngsøe

Department of Paediatrics, Hillerød University Hospital, Hillerød, Denmark

M. H. Lauridsen • N. H. Birkebæk

Department of Paediatrics, Aarhus University Hospital, Skejby,

Denmark

B. Hertz

Department of Paediatrics, Viborg Regional Hospital, Viborg,

Denmark until 1 January 2012. Repeated-measurement models were used as statistical methods.

Results The study population comprised 2,964 children $<18$ years. The prevalence of DKA at diagnosis was $17.9 \%$. Of the total subjects, $8.3 \%$ had mild, $7.9 \%$ had moderate and $1.7 \%$ had severe DKA. DKA (moderate and severe) was associated with increased $\mathrm{HbA}_{1 \mathrm{c}}$ (\%) levels $(0.24 ; 95 \%$ CI 0.11 , 0.36 ; $p=0.0003$ ) and increased insulin dose-adjusted $\mathrm{HbA}_{1 \mathrm{c}}$ (IDAA $_{1 \mathrm{c}}, 0.51 ; 95 \%$ CI $0.31,0.70 ; p<0.0001$ ) during followup, after adjustment for covariates. Children without a family history of diabetes were more likely to present with DKA $(19.2 \%$ vs $8.8 \%, p<0.0001)$; however, these children had a lower $\mathrm{HbA}_{1 \mathrm{c}}(\%)$ level over time $(-0.35 ; 95 \% \mathrm{CI}-0.46,-0.24$; $p<0.0001)$. Continuous subcutaneous insulin infusion (CSII) was associated with a long-term reduction in $\mathrm{HbA}_{1 \mathrm{c}}$, changing the effect of DKA, after adjustment for covariates $(p<0.0001)$. Conclusions/interpretation DKA at diagnosis was associated with poor long-term metabolic regulation and residual beta cell function as assessed by $\mathrm{HbA}_{1 \mathrm{c}}$ and $\mathrm{IDAA}_{1 \mathrm{c}}$, respectively; however, CSII treatment was associated with improvement in glycaemic regulation and residual beta cell function, changing the effect of DKA at onset in our population.

Keywords Denmark - Diabetic ketoacidosis · DKA . Metabolic regulation · Onset · Paediatric · Treatment regimen · Type 1 diabetes
Abbreviations
CSII Continuous subcutaneous insulin infusion
DKA Diabetic ketoacidosis
IDAA $_{1 \mathrm{c}}$ Insulin dose-adjusted $\mathrm{HbA}_{1 \mathrm{c}}$
MDI Multiple daily injections
TEDDY The Environmental Determinants of Diabetes in the Young 


\section{Introduction}

Diabetic ketoacidosis (DKA) at onset, an acute complication due to insufficient insulin production, is present in up to $67 \%$ of children at the initial presentation of type 1 diabetes [1-5]. Mortality due to cerebral oedema after DKA occurs in $0.3-1 \%$ of newly diagnosed children $[6,7]$. A worldwide increase in type 1 diabetes has been reported $[8,9]$, and is particularly evident in younger children $(<5$ years $)$. In addition, the youngest children are at increased risk of presenting with metabolic deterioration $[3,4,10-12]$ due to delayed diagnosis, leading to advanced deterioration at onset $[13,14]$ and/or a more aggressive aetiology $[15,16]$.

The UK has observed an increase in DKA at presentation in recent years [17], while reports from Sweden and northern Finland have noted a decrease over time [3,5], and Germany and Austria have reported no changes in DKA incidence over the past two decades [15]. These populationbased surveys represent countries with a high annual background incidence of type 1 diabetes comparable with that of Denmark [18]. Elding Larsson et al, who followed-up and screened children genetically at risk of diabetes for diabetesspecific autoantibodies in a multinational study, found that participation in the study was associated with reduced risk of DKA [19]. However, despite prevention campaigns and an improved system of medical care [20,21], the rate of DKA remains unacceptably high.

In many patients, the clinical course of type 1 diabetes during the first year is characterised by residual endogenous insulin secretion (the remission phase) $[16,22,23]$. The heterogeneity of the remission phase and its duration are influenced by several factors. Fernandez et al found that children with severe metabolic deterioration at the time of diagnosis had lower residual beta cell function and poor glycaemic regulation up to 2 years after diagnosis [23]. Pinkey et al observed no association between the presence of DKA at diagnosis and long-term glycaemic regulation during a 4-year prospective follow-up period [17].

New advances in type 1 diabetes treatment regimens over the past decade call for a thorough evaluation of our efforts to improve metabolic outcome in children. The purpose of the present study is to: (1) describe DKA at the initial presentation of type 1 diabetes; (2) assess the association between DKA at onset with outcome measured as $\mathrm{HbA}_{1 \mathrm{c}}$ and insulin dose-adjusted $\mathrm{HbA}_{1 \mathrm{c}}$ (IDAA $\mathrm{Ic}_{1 \mathrm{c}}$ ) during followup; and (3) investigate the influence of treatment regimens in a Danish paediatric population.

\section{Methods}

Subjects We conducted a register-based follow-up study of children newly diagnosed with type 1 diabetes aged 0 to 18 from 1996 to 2009. The new cases were drawn from a background population in Denmark of approximately one million children. The five health districts serving this population comprise 18 paediatric diabetes centres with a reported overall type 1 diabetes incidence rate of 22 per 100,000 inhabitants [24]. Exclusion criteria were patients diagnosed with, or suspected of, non-type 1 diabetes (maturity-onset diabetes of the young, type 2 diabetes, secondary diabetes, etc.). We stratified our patients into four groups according to age at diagnosis: $<5$ years, $5-10$ years, 10 15 years, and adolescents $>15$ years of age.

Data collection Patients were diagnosed with type 1 diabetes according to the WHO criteria [25]. The date of the first insulin injection was considered to be the date of diagnosis. Data collected were baseline data (including ethnicity and family history of any type of diabetes in first-degree relatives), biochemical data at onset $\left(\mathrm{HbA}_{1 \mathrm{c}}\right.$, blood glucose concentration, bicarbonate and/or venous $\mathrm{pH}$ ), prospective records of diabetes treatment regimens (route of administration, multiple daily injections [MDI], continuous subcutaneous insulin infusion [CSII]), daily insulin dosage/kg body weight, frequency of daily blood glucose measurements, acute complications (DKA and hypoglycaemia) and annual recordings for centralised measurements of $\mathrm{HbA}_{1 \mathrm{c}}$ and $\mathrm{IDAA}_{1 \mathrm{c}}$.

Data completeness In Denmark, all children and adolescents suspected of having type 1 diabetes are referred to a tertiary unit, and if the diagnosis is verified, they are recorded on a standard registration form submitted to DanDiabKids. The register, founded in 1996, annually undergoes capture-recapture methodology based on records from the individual paediatric diabetes centres and the Danish National Patient Register to ascertain data completeness (currently at 99\%) [26]. DanDiabKids does not require centralised measures of $\mathrm{HbA}_{1 \mathrm{c}}$ and IDAA $\mathrm{Ac}_{1 \mathrm{c}}$ in the first 3 months after diagnosis; these measurements are analysed locally and are consequently not representative for comparisons. Data completeness for $\mathrm{HbA}_{1 \mathrm{c}}$ and $\mathrm{IDAA}_{1 \mathrm{c}}$ is $90.2 \%$ and $85.0 \%$, respectively, and is calculated on the basis of the number of recordings with missing information regarding $\mathrm{HbA}_{1 \mathrm{c}}$ and/or the requirement of insulin.

Definition of DKA In our study, the European Society for Paediatric Endocrinology/Lawson Wilkins Pediatric Endocrine Society consensus statement, which is in agreement with recommendations endorsed by ISPAD Clinical Practice Consensus Guidelines 2006-2007, was used to define DKA and classify the severity of DKA $[18,27]$. Blood glucose $>11 \mathrm{mmol} / \mathrm{l}(\sim 200 \mathrm{mg} / \mathrm{dl})$, ketonuria and/or ketonaemia, and a venous $\mathrm{pH}$ value $<7.30$ marked the biochemical criterion for DKA [27]. The severity of DKA was classified as mild 
$(7.20 \leq \mathrm{pH}<7.30$ or bicarbonate $<15 \mathrm{mmol} / \mathrm{l})$, moderate $(7.10 \leq \mathrm{pH}<7.20$ or bicarbonate $<10 \mathrm{mmol} / \mathrm{l})$ or severe $(\mathrm{pH}$ $<7.10$, bicarbonate $<5 \mathrm{mmol} / \mathrm{l}$ ). The definition of no DKA was standard bicarbonate $\geq 15 \mathrm{mmol} / 1$ or $\mathrm{pH} \geq 7.30$.

Glycated $H b A_{l c} \mathrm{HbA}_{1 \mathrm{c}}$ was locally analysed in a specialised laboratory at the respective tertiary hospital units at disease onset. During follow-up, the blood samples for $\mathrm{HbA}_{1 \mathrm{c}}$ analysis were handled annually in a centralised laboratory at Herlev Hospital, Copenhagen, using a high-pressure liquid chromatographic method (Tosoh Bioscience, South San Francisco, CA, USA). The DCCT reference method was used for $\mathrm{HbA}_{1 \mathrm{c}}$ values if not otherwise specified, with a non-diabetic reference range of $4.3-5.8 \%$ (corresponding to the International Federation of Clinical Chemistry [IFCC] $\mathrm{HbA}_{1 \mathrm{c}}$ values of $23-40 \mathrm{mmol} / \mathrm{mol}$ ). The $\mathrm{HbA}_{1 \mathrm{c}}$ values have been validated by the European Reference Laboratory and are in line with the DCCT values.

$I D A A_{1 c}$ Residual beta cell function was assessed by IDAA $A_{1 c}$ calculated as follows: current $\mathrm{HbA}_{1 \mathrm{c}}(\%)+[4 \times$ insulin dosage $\left(\mathrm{Ukg}^{-1}\right.$ day $\left.\left.^{-1}\right)\right][28]$.

Statistical analysis Statistical analyses were performed using SAS version 9.2 (SAS Institute, Cary, NC, USA). Prevalence and demographic characteristics were analysed. Logistic regression models for ordinal measures were used to estimate $p$ values to analyse the differences in prevalence of DKA between regions/centres, sex, age, family history of diabetes and ethnicity. The data comprised longitudinal and repeated-measures data with several predictor variables. Repeated-measurement models (named 'proc mixed procedure' in SAS) were used to quantify the relationship between glycaemic regulation and residual beta cell function and the various explanatory variables. A constant correlation within the individual patient over time was assumed for the repeated measurements of $\mathrm{HbA}_{1 \mathrm{c}}$ and $\mathrm{IDAA}_{1 \mathrm{c}}$. The covariance structure assumed for all statistical models included age, sex, duration of diabetes, ethnicity, family history of diabetes, and centre difference, with a random intercept for each individual. Subsequently, the models were individually fitted with the covariates of treatment regimen, duration of CSII therapy and DKA, as indicated in the respective models. The $\mathrm{HbA}_{1 \mathrm{c}}$ and $\mathrm{IDAA}_{1 \mathrm{c}}$ results were considered fixed variables, whereas duration of diabetes, duration of CSII treatment, and treatment regimen were considered time-dependent covariates. Patients who were receiving CSII for less than 3 months were considered to be in the MDI category. A $p$ value $<0.05$ was considered significant.

Patients diagnosed with mild and no DKA comprised a homogeneous group in our population in terms of baseline data (sex, age at onset, ethnicity and family history of diabetes); similar patients diagnosed with moderate and severe DKA were homogeneous. All patients were therefore stratified into a dichotomous variable (none/mild and moderate/severe DKA), and analysed as specified in the following. The frequency of moderate/severe DKA at diagnosis among immigrant children and offspring of immigrants did not differ significantly; hence, we chose to analyse this group as one in the statistical model assessing time trend and geographical variation. A small number of patients were on MDI using indwelling subcutaneous catheters (81 subjects); hence, we chose to include these patients in the MDI category.

\section{Results}

We identified 3,332 children and adolescents newly diagnosed with type 1 diabetes from 1996 to 2009 and followed them prospectively until 1 January 2012. Owing to missing data for DKA verification at diagnosis, $368(11.0 \%)$ subjects were not eligible for inclusion. We enrolled 2,964 patients in the study, $1,420(47.9 \%)$ of whom were girls. The mean age was 9.17 years $(95 \%$ CI 9.02, 9.31).

Biochemical data at onset The mean $\mathrm{HbA}_{1 \mathrm{c}}$ level in the study population was $11.3 \%$ (95\% CI $11.2 \%, 11.5 \%)$, corresponding to $100 \mathrm{mmol} / \mathrm{mol}(95 \%$ CI 99,102$)$, before initiation of insulin therapy. The mean blood glucose at diagnosis was $27.2 \mathrm{mmol} / 1$ (95\% CI 26.6, 27.7), corresponding to $490.1 \mathrm{mg} / \mathrm{dl}(95 \%$ CI $479.3,499.1)$.

We observed a significant difference in $\mathrm{HbA}_{1 \mathrm{c}}$ at onset according to the different age groups $(p=0.0001)$. Children $<5$ years had the lowest $\mathrm{HbA}_{1 \mathrm{c}}$ (mean $9.9 \%(\sim 85 \mathrm{mmol} / \mathrm{mol}$ ), $\mathrm{SD} 1.7 \%$ ), and $\mathrm{HbA}_{1 \mathrm{c}}$ increased with each successively older age group. There were no differences in blood glucose at onset between age groups $(p=0.15)$.

DKA at diagnosis of type 1 diabetes Out of 2,964 children and adolescents, 529 (17.9\%) were diagnosed with DKA (venous $\mathrm{pH}<7.30$ or bicarbonate $<15 \mathrm{mmol} / \mathrm{l}$ ). Table 1 shows demographic characteristics and the prevalence of DKA in our Danish population (electronic supplementary material [ESM] Table 1 illustrates raw data, and ESM Table 2 summarises the prevalence of DKA elsewhere). Of the 2,964 subjects, 245 (8.3\%) had mild DKA, 235 (7.9\%) had moderate DKA, and $49(1.7 \%)$ had severe DKA at onset according to the definition. Almost half of the children $<2$ years of age had DKA: $17.9 \%$ had mild DKA, $28.3 \%$ had moderate, and $2.1 \%$ had severe DKA. DKA prevalence did not differ significantly between sexes $(p=0.27)$. Table 2 lists the characteristics of the patients according to severity of DKA as well as indicators during follow-up. 
Table 1 Characteristics of patients and prevalence of DKA at diagnosis, unadjusted (2,964 patients)

\begin{tabular}{|c|c|c|c|}
\hline \multirow[t]{2}{*}{ Characteristic } & \multicolumn{2}{|c|}{ DKA prevalence } & \multirow[t]{2}{*}{$p$ value } \\
\hline & $n / N$ & Prevalence $(\%)$ & \\
\hline All & $529 / 2,964$ & 17.9 & \\
\hline Age at diagnosis (years) & & & $<0.0001$ \\
\hline 0 to $<5$ & $145 / 574$ & 25.3 & \\
\hline 5 to $<10$ & $128 / 983$ & 13.0 & \\
\hline 10 to $<15$ & $241 / 1,300$ & 18.5 & \\
\hline$\geq 15$ & $15 / 107$ & 14.0 & \\
\hline Sex & & & 0.27 \\
\hline Girls & $265 / 1,420$ & 18.7 & \\
\hline Boys & $264 / 1,544$ & 17.1 & \\
\hline Ethnicity & & & $<0.0001$ \\
\hline Danish & $475 / 2,782$ & 17.1 & \\
\hline Immigrants & $41 / 143$ & 28.7 & \\
\hline Offspring of immigrants & $13 / 39$ & 33.3 & \\
\hline Family history of diabetes ${ }^{\mathrm{a}}$ & & & $<0.0001$ \\
\hline Yes & $34 / 388$ & 8.8 & \\
\hline No & $487 / 2,541$ & 19.2 & \\
\hline Region & & & 0.03 \\
\hline Region of Northern Denmark & $53 / 374$ & 14.2 & \\
\hline Region of Central Denmark & $99 / 661$ & 15.0 & \\
\hline Region of Eastern Denmark & $86 / 472$ & 18.2 & \\
\hline Region of Southern Denmark & $126 / 676$ & 18.6 & \\
\hline Capital Region of Copenhagen & $165 / 781$ & 21.1 & \\
\hline
\end{tabular}

DKA, $\mathrm{pH}<7.3$ or standard bicarbonate $<15 \mathrm{mmol} / 1$

${ }^{a}$ Data on family history of any type of diabetes in biological siblings or parents at diagnosis was missing in $35(1.2 \%)$ patients

Prevalence of DKA over time When 1996-2009 is stratified into three periods, we found significant differences between time periods in the prevalence of moderate/severe DKA from the first to the last period: $9.7 \%$ for $1996-2000$, $8.0 \%$ for $2001-2005$, and $11.4 \%$ for 2006-2009 (unadjusted: $p=0.024$; adjusted: $p=0.019$ ).

Regional variation The DKA prevalence at onset differed between the various regions $(p=0.03)$ and between the different tertiary units $(p=0.02)$. This difference in DKA prevalence, however, disappeared when DKA was stratified into none/mild and moderate/severe DKA, both with respect to regions $(p=0.06)$ and tertiary units $(p=0.05)$.

Metabolic regulation as assessed by long-term $\mathrm{Hb} A_{1 c}$ during follow-up We found an association of DKA at onset with metabolic regulation measured as $\mathrm{HbA}_{1 \mathrm{c}}$ during follow-up (after adjustments for other covariates, including treatment regimen and duration of CSII treatment), with a significantly higher $\mathrm{HbA}_{1 \mathrm{c}}$ over time for children presenting with moderate and severe DKA $(0.24,95 \%$ CI $0.11,0.36$; $p=0.0003$, Table 3 ). There was a significant interaction between DKA and duration of diabetes $(p=0.0036)$. Figure 1a illustrates the differences in $\mathrm{HbA}_{1 \mathrm{c}}$ over time according to classification of DKA at onset.

Residual beta cell function as assessed by IDAA 1 during follow-up Our analysis shows associations of DKA at onset with residual beta cell function as assessed by IDAA $_{1 \mathrm{c}}$, where we detected a significantly higher IDAA $_{1 c}$ level over time (reduced beta cell function) for patients presenting with moderate and severe DKA $(0.51,95 \%$ CI 0.32 , $0.70 ; p<0.0001$, Table 3 ) after adjustment for covariates, including treatment regimen and duration of CSII treatment. Here also we found a significant interaction between DKA and duration of diabetes $(p<0.0001)$. Figure $1 \mathrm{~b}$ illustrates the differences in IDAA $_{1 \mathrm{c}}$ over time according to classification of DKA at onset.

Treatment regimen during follow-up Repeated-measurement models were used to analyse the effect of treatment regimen on long-term glycaemic regulation and residual beta cell function as assessed by $\mathrm{HbA}_{1 \mathrm{c}}$ and $\mathrm{IDAA}_{1 \mathrm{c}}$, respectively. The additional covariates fitted in the model include the duration of CSII treatment, DKA and centre differences. The interaction between DKA and treatment regimen assessed by the duration of CSII treatment (where MDI-treated patients were treated as zero) was highly significant $(p<0.0001)$, and the data indicate that CSII was associated with improved long-term $\mathrm{HbA}_{1 \mathrm{c}}$ and $\mathrm{IDAA}_{1 \mathrm{c}}$, changing the effect of DKA ( $p<0.0001$, ESM Fig. 1a, b). In ESM Fig. 2, the predicted $\mathrm{HbA}_{1 \mathrm{c}}$ values in this model for CSII- and MDI-treated patients are illustrated for patients with a diabetes duration of 2-4 years (ESM Fig. 2a) and $>4$ years (ESM Fig. $2 b$ ) with respect to duration of CSII treatment.

\section{Discussion}

In our study the prevalence of DKA was $17.9 \%$, with $9.6 \%$ of the cases presenting with moderate and/or severe DKA ( $\mathrm{pH}<7.2$ and/or bicarbonate $<10 \mathrm{mmol} / \mathrm{l})$. We found significant differences between time periods in the prevalence of DKA $(p=0.019)$. Our data demonstrate that DKA (moderate/severe) is associated with a higher long-term $\mathrm{HbA}_{1 \mathrm{c}}$ level as well as a higher IDAA $_{1 c}$ during follow-up compared with none/mild DKA at onset. Children with a family history of diabetes suffered less frequently from DKA $(8.8 \%$ vs 19.2\%); however, these children had a higher $\mathrm{HbA}_{1 \mathrm{c}}$ level over time. CSII was associated with a reduction in long-term $\mathrm{HbA}_{1 \mathrm{c}}$ and $\mathrm{IDAA}_{1 \mathrm{c}}$ results, changing the effect of DKA at onset. 
Table 2 Characteristics of patients stratified by classification of DKA, unadjusted (2,964 patients)

\begin{tabular}{|c|c|c|c|c|}
\hline Characteristic & Data completeness $(\%)$ & None/mild DKA & Moderate/severe DKA & $p$ value \\
\hline All, $n / N$ & & $2,680 / 2,964$ & $284 / 2,964$ & \\
\hline Prevalence $(\%)$ & & 90.4 & 9.6 & \\
\hline Age at diagnosis (years), $n(\%)$ & 100.0 & & & $<0.0001$ \\
\hline 0 to $<5$ & & $496(86.4)$ & $78(13.6)$ & \\
\hline 5 to $<10$ & & $920(93.6)$ & $63(6.4)$ & \\
\hline 10 to $<15$ & & $1,166(89.7)$ & $134(10.3)$ & \\
\hline$\geq 15$ & & $98(91.6)$ & $9(8.4)$ & \\
\hline $\mathrm{HbA}_{1 \mathrm{c}}(\%)$ at diagnosis ${ }^{\mathrm{a}}$ & 19.0 & $11.21(2.33)$ & $12.37(2.20)$ & $<0.0001$ \\
\hline $\mathrm{HbA}_{1 \mathrm{c}}(\sim \mathrm{mmol} / \mathrm{mol})$ at diagnosis ${ }^{\mathrm{a}}$ & 19.0 & $\sim 99$ & $\sim 112$ & $<0.0001$ \\
\hline $\mathrm{HbA}_{1 \mathrm{c}}(\%)$ during follow-up ${ }^{\mathrm{b}}$ & 90.2 & $8.34(1.34)$ & $8.50(1.40)$ & 0.11 \\
\hline $\mathrm{HbA}_{1 \mathrm{c}}(\sim \mathrm{mmol} / \mathrm{mol})$ during follow-up ${ }^{\mathrm{b}}$ & 90.2 & $\sim 67.7$ & $\sim 69.4$ & 0.11 \\
\hline Duration of diabetes (years) & 100.0 & $5.84(3.19)$ & $5.73(3.39)$ & 0.59 \\
\hline Number of blood glucose measurements/week at latest follow-up & 88.2 & $38.2(16.9)$ & $37.2(16.4)$ & 0.40 \\
\hline IDAA $_{1 \mathrm{c}}, 6-18$ months after diagnosis ${ }^{\mathrm{c}}$ & 85.0 & $10.71(1.89)$ & $11.40(2.00)$ & 0.0001 \\
\hline Insulin requirements $\left(\mathrm{Ukg}^{-1}\right.$ day $\left.^{-1}\right)$ at latest follow-up & 91.8 & $0.99(0.34)$ & $1.00(0.34)$ & 0.75 \\
\hline Insulin regimen at latest follow-up, $n$ (column \%) & 91.8 & & & 0.14 \\
\hline $\mathrm{MDI}^{\mathrm{d}}$ & & $1,534(61.4)$ & $149(56.7)$ & \\
\hline CSII & & $965(38.6)$ & $114(43.3)$ & \\
\hline $\begin{array}{l}\text { The number of severe hypoglycaemic events during follow-up } \\
\text { per } 100 \text { patient-years }\end{array}$ & 91.6 & 12.9 & 12.3 & 0.25 \\
\hline Standard BMI at onset $\left(\mathrm{kg} / \mathrm{m}^{2}\right)$ & 92.8 & $0.86(1.37)$ & $0.75(1.32)$ & 0.25 \\
\hline A positive family history of diabetes ${ }^{\mathrm{f}}, n$ (row $\left.\%\right)$ & 97.5 & $372(95.9)$ & $16(4.1)$ & $<0.0001$ \\
\hline
\end{tabular}

Continuous variables are expressed as mean $( \pm \mathrm{SD})$ unless otherwise indicated

DKA, $\mathrm{pH}<7.3$ or standard bicarbonate $<15 \mathrm{mmol} / 1$

${ }^{\mathrm{a}} \mathrm{HbA}_{1 \mathrm{c}}$ before initiation of insulin treatment

${ }^{\mathrm{b}} \mathrm{HbA}_{1 \mathrm{c}}$ analysed centrally; mean $( \pm \mathrm{SD})$ is calculated from the repeated measurements on the patient during follow-up with only HbA $\mathrm{A}_{1 \mathrm{c}}$ in the model (unadjusted)

${ }^{\mathrm{c}} \mathrm{IDAA}_{1 \mathrm{c}}$ : current $\mathrm{HbA}_{1 \mathrm{c}}(\%)+\left[4 \times\right.$ insulin dosage $\left(\mathrm{Ukg}^{-1}\right.$ day $\left.\left.{ }^{-1}\right)\right]$

${ }^{\mathrm{d}}$ Including patients using indwelling subcutaneous catheters

${ }^{\text {e }}$ Severe hypoglycaemia was defined as unconsciousness or seizures, requirement of assistance, and, if measured, a blood glucose level of $<3.5 \mathrm{mmol} / 1$

${ }^{\mathrm{f}}$ A family history of any type of diabetes in biological siblings or parents at diagnosis

The observed frequency of DKA in our population is in line with countries geographically near Denmark. A higher DKA rate was observed in the youngest age group $(<5$ years), which is consistent with previous studies undertaken in countries with a high incidence of type 1 diabetes $[4,10,14,16,29]$. The very young children $(<2$ years $)$ had an undesirably high prevalence of DKA (48.3\%), comparable with register studies from Sweden, Finland and Germany $(39.5-54.9 \%)[15,30,31]$. The subtlety of the symptoms in infants and toddlers presents a challenge in diagnosing this age group [32]. Underlying aggressive beta cell destruction and a high risk of dehydration in this age group might also predispose the youngest children to be more vulnerable to metabolic derangements. Adolescents $10-15$ years of age were also at high risk of DKA. The transition from childhood to adolescence and the child's appertaining independence-seeking behaviour, possibly complicated by physiological changes in multiple hormones accompanying puberty, might cause symptom neglect and progression into DKA. Individual and inter-personal factors, including personality types, mental health issues, peer relationships and family dynamics, may also have an important influence on both initial presentation and future glycaemic regulation, possibly with similarities to the challenges reported by adolescents and to their experiences of living with type 1 diabetes [33].

Consistent with previous studies, we detected an unfortunately high frequency of DKA in children from ethnic minorities [14]. The reason for this high prevalence of DKA in this patient group is multifactorial, but it might well reflect language barriers, socioeconomic and cultural inequities, and differences in health-seeking behaviour. Parental 
Table 3 Results of the repeated-measurement models with DKA as the dependent variable and $\mathrm{HbA}_{1 \mathrm{c}}$ and IDAA $\mathrm{Ac}_{\mathrm{c}}$ as the outcome variables during follow-up for 2,929 patients (after adjustment for treatment regimen, centre differences and duration of CSII treatment)

\begin{tabular}{|c|c|c|c|c|c|c|}
\hline \multirow[t]{2}{*}{ Variable } & \multicolumn{3}{|c|}{ Linear mixed model, $\mathrm{HbA}_{1 \mathrm{c}}(\%)$} & \multicolumn{3}{|c|}{ Linear mixed model, IDAA $_{1 \mathrm{c}}{ }^{\mathrm{a}}$} \\
\hline & Estimate & $95 \% \mathrm{CI}$ & $p$ value & Estimate & $95 \% \mathrm{CI}$ & $p$ value \\
\hline \multicolumn{7}{|l|}{ Unadjusted model } \\
\hline Severity of DKA at onset & & & 0.0009 & & & $<0.0001$ \\
\hline None/mild ${ }^{\mathrm{b}}$ & 0 & 0 & & 0 & 0 & \\
\hline Moderate/severe & 0.23 & $0.09,0.36$ & & 0.42 & $0.21,0.64$ & \\
\hline \multicolumn{7}{|l|}{ Adjusted model } \\
\hline Severity of DKA at onset & & & 0.0003 & & & $<0.0001$ \\
\hline None/mild ${ }^{\mathrm{b}}$ & 0 & 0 & & 0 & 0 & \\
\hline Moderate/severe & $0.24^{\mathrm{c}}$ & $0.11,0.36$ & & 0.51 & $0.31,0.70$ & \\
\hline Age at diagnosis (years) & & & $<0.0001$ & & & $<0.0001$ \\
\hline 0 to $<5$ & -0.23 & $-0.33,-0.13$ & & -0.63 & $-0.79,-0.47$ & \\
\hline 5 to $<10^{\mathrm{b}}$ & 0 & 0 & 0 & 0 & 0 & \\
\hline 10 to $<15$ & 0.25 & $0.17,0.34$ & & 0.40 & $0.27,0.52$ & \\
\hline$\geq 15$ & -0.12 & $-0.36,-0.11$ & & -0.24 & $-0.61,0.12$ & \\
\hline Sex & & & 0.80 & & & 0.02 \\
\hline Girl & -0.01 & $-0.08,0.06$ & & 0.14 & $0.03,0.25$ & \\
\hline Boy $^{b}$ & 0 & & & 0 & & \\
\hline Ethnicity & & & $<0.0001$ & & & $<0.0001$ \\
\hline Danish & -0.52 & $-0.68,-0.35$ & & -0.51 & $-0.76,-0.26$ & \\
\hline Immigrants and offspring of immigrants ${ }^{\mathrm{b}}$ & 0 & 0 & & 0 & 0 & \\
\hline Family history of diabetes & & & $<0.0001$ & & & $<0.0001$ \\
\hline No & -0.35 & $-0.46,-0.24$ & & -0.41 & $-0.58,-0.24$ & \\
\hline Yes $^{\mathrm{b}}$ & 0 & 0 & & 0 & 0 & \\
\hline Duration of CSII treatments & & & $<0.0001$ & & & $<0.0001$ \\
\hline MDI, or CSII $<3$ months ${ }^{b, d}$ & 0 & 0 & & 0 & 0 & \\
\hline 3 months to 1 year $^{\mathrm{e}}$ & -0.26 & $-0.33,-0.18$ & & -0.90 & $-0.99,-0.80$ & \\
\hline 1 to $<2$ years $^{\mathrm{e}}$ & -0.17 & $-0.25,-0.10$ & & e & e & \\
\hline 2 to $<4$ years & -0.02 & $-0.09,0.06$ & & -0.91 & $-1.03,-0.80$ & \\
\hline$\geq 4$ years & 0.29 & $0.07,0.33$ & & -0.53 & $-0.75,-0.31$ & \\
\hline Duration of diabetes (years) & & & $<0.0001$ & & & $<0.0001$ \\
\hline 0 to $<1$ & -0.86 & $-0.91,-0.80$ & & -2.64 & $-2.74,-2.54$ & \\
\hline 1 to $<2$ & -0.46 & $-0.51,-0.41$ & & -1.39 & $-1.48,-1.30$ & \\
\hline 2 to $<4$ & -0.21 & $-0.25,-0.17$ & & -0.55 & $-0.61,-0.48$ & \\
\hline$\geq 4^{\mathrm{b}}$ & 0 & 0 & & 0 & 0 & \\
\hline
\end{tabular}

${ }^{\mathrm{a}} \mathrm{IDAA}_{1 \mathrm{c}}$ : current $\mathrm{HbA}_{1 \mathrm{c}}(\%)+\left[4 \times\right.$ insulin dosage $\left(\mathrm{Ukg}^{-1}\right.$ day $\left.\left.{ }^{-1}\right)\right]$

${ }^{\mathrm{b}}$ The reference group used in the statistical model

c i.e. children presenting in moderate/severe DKA at onset have a $0.24 \%$ higher $\mathrm{HbA}_{1 \mathrm{c}}$ during follow-up than children presenting with none/mild DKA

${ }^{\mathrm{d}}$ The MDI patients and patients with a duration of CSII treatment $<3$ months are categorised as MDI

${ }^{\mathrm{e}}$ The model with $\mathrm{IDAA}_{1 \mathrm{c}}$ as outcome variable was not applicable due to infinite likelihood. We combined the groups of CSII duration from 3 months to 2 years, and the estimates are illustrated accordingly

consanguinity, leading to speculations of different aetiology of beta cell destruction, was not associated with differences in the rate of DKA in a study from Saudi Arabia [34]. However, additional studies are needed to explore differences between racial groups.
The frequency of DKA in children with a family history of diabetes was somewhat lower than in the TEDDY (The Environmental Determinants of Diabetes in the Young) Study (8.8\% vs $11.3 \%$ ) [19], although the TEDDY Study only comprised patients under the age of five, who were 


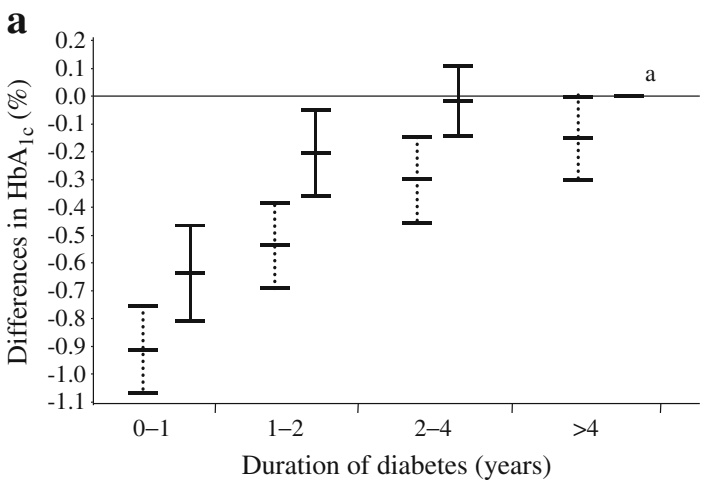

Fig. 1 (a) Glycaemic regulation measured as differences in $\mathrm{HbA}_{1 \mathrm{c}}(\%)$ and (b) residual beta cell function measured as differences in insulin dose-adjusted $\mathrm{HbA}_{1 \mathrm{c}}(\%)\left(\mathrm{IDAA}_{1 \mathrm{c}}\right.$ ) during follow-up in 2,923 patients according to classification of DKA at onset. Values are mean $( \pm \mathrm{SD})$. Solid line, moderate and severe DKA; dotted line, none and mild DKA. In (b) a high IDAA $A_{1 c}$ value corresponds to a low level of endogenous

intensely followed before and after the time of diagnosis [19]. We found that a family history of diabetes was a preventive factor for presenting with DKA; however, this 'advantage' seemed to diminish over time in our population, as these patients were observed with a higher long-term $\mathrm{HbA}_{1 \mathrm{c}}$ during follow-up. Increased awareness in families with previous experience of diabetes, but also increased alertness among family physicians, might predispose to a milder onset of disease, and finally a heterogeneity within the autoimmune and genetic risk [35]. The worse metabolic outcome in those patients with a family history of diabetes was not explained by differences in treatment regimens. Thus, the data in this patient group are too scant to draw any conclusions, and further analysis regarding the effect of treatment on this particular group was unfortunately not applicable.

Children diagnosed with moderate/severe DKA did not differ from children with none/mild DKA on comparison of BMI standard deviation score at onset, the frequency of blood glucose measurements, insulin requirements, treatment regimen or the frequency of severe hypoglycaemia during followup. IDAA $A_{1 \mathrm{c}}$, an indirect marker of beta cell function, was found to be significantly higher 6-18 months after onset in children with moderate/severe DKA (implying reduced beta cell function), but IDAA $A_{1 c}$ was also found to be significantly higher during follow-up in this patient group, reflecting increased $\mathrm{HbA}_{1 \mathrm{c}}$ and/or a lower insulin sensitivity, and consequently a higher insulin requirement to obtain normoglycaemia. This is in line with the higher $\mathrm{HbA}_{1 \mathrm{c}}$ observed during follow-up in patients with moderate/severe DKA.

Interestingly, our data indicate that the effect of DKA at onset on long-term glycaemic regulation and residual beta cell function is changed by an intensive treatment regimen (CSII). However, it has to be taken into account that residual beta cell function in these calculations is based on insulin dose, which is known to be lower in CSII-treated patients.

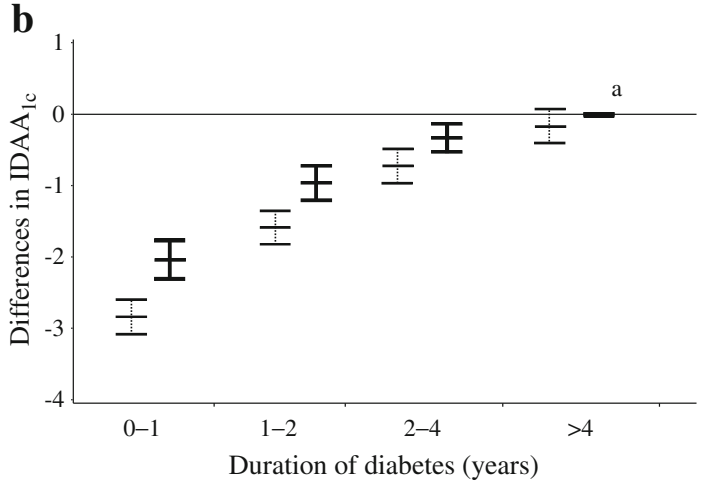

insulin production. The difference between the DKA groups was highly significant ( $p=0.00036$ in $\mathbf{a} ; p<0.0001$ in b). ${ }^{\mathrm{a}}$ The reference group in this model was moderate/severe DKA with a duration of diabetes $>4$ years (adjusted for age, sex, duration of diabetes, ethnicity, family history of diabetes, treatment regimen, centre differences and duration of CSII treatment)

We observed improved glycaemic regulation when patients were started on CSII, and the differences between DKA groups disappeared within the first year of CSII treatment. The initial improvement in glycaemic regulation might be due to the fact that the patients and their families receive thorough professional education at the initiation of CSII treatment. One year after initiation of CSII treatment, the glycaemic regulation worsens, and the differences between patients with deterioration at onset tend to reappear. We question whether it would be beneficial to re-educate the patients at this time, to increase awareness and improve compliance to alter this worsening of glycaemic regulation.

On 1 January 2012, the frequency of children on CSII in our population was $39.1 \%$ and is steadily increasing. Of the children on CSII, native Danish children represent $96.0 \%$ of the group, while immigrant children represent $2.8 \%$ and offspring of immigrants $1.2 \%$. These data are therefore representative of the proportion of non-Danish patients $(6.1 \%)$ in our population. However, one might debate whether the patients on CSII are highly selected and represent families with the necessary resources to achieve optimal adherence in the daily management of diabetes, thereby improving glycaemic regulation. Our data are in line with previous knowledge that tight metabolic regulation helps sustain endogenous insulin production and consequently improves longterm metabolic regulation as described in the DCCT Study [36]. Denmark offers a high level of healthcare provision with equal access for all citizens, enabling early diagnosis and the opportunity for tight metabolic regulation. However, compliance is a cornerstone of successful treatment in the pursuit to achieve optimal metabolic regulation in this patient group.

Strengths and weaknesses The fact that the DanDiabKids register has $99 \%$ data completeness enables a thorough investigation of our paediatric diabetes patients in Denmark. 
The study population comprised hospital-referred patients diagnosed at tertiary treatment units. This might positively influence an early diagnosis throughout Denmark and result in a low frequency of DKA compared with other countries. A limitation of this study is the locally analysed $\mathrm{HbA}_{1 \mathrm{c}}$ results at initial diagnosis assigned to the respective hospital units around the country. A strength, however, is the centrally organised laboratory unit used for annual samples of $\mathrm{HbA}_{1 \mathrm{c}}$ measurements throughout the study period, which were frequently validated and aligned with the DCCT values. We did not have data on the insulin analogues administered. Recent advances in new insulin analogues and differentiation of their effects will be of pivotal interest in future studies focusing on treatment modalities.

In conclusion, we found an increased risk of poor longterm glycaemic regulation and reduced residual beta cell function in children presenting with moderate/severe DKA at onset of type 1 diabetes. However, an intensive treatment regimen limited the negative effect of DKA at onset, with improved glycaemic regulation and residual beta cell function during follow-up, which was also true when centre differences were taken into account. The optimal time for CSII initiation, continuous education and strategies to decrease DKA at onset need to be evaluated in different populations to improve longterm outcome in this patient group.

Acknowledgements We are grateful to the paediatricians and nurses who provided us with patient information. We would also like to thank our bioanalyst, J. Høgsmose, at Herlev Hospital for expert handling of blood samples and data management, and C. Bressen Pipper from the University of Copenhagen, Biostatistics Department, for statistical advice.

Funding This study was supported by the Danish Society for Diabetes in Childhood and Adolescence and The Faculty of Health and Medical Sciences, Copenhagen University.

Duality of interest The authors declare that there is no duality of interest associated with this manuscript.

Contribution statement SF was involved in study conception and design, acquisition of data, data analysis and interpretation, writing of the manuscript. JJ, HBM and JS were involved in study conception and design, acquisition of data, data analysis and interpretation, manuscript revision. AJ, LL, HR, MLMA, MHL, BH, NHB and BO were involved in study conception and design, acquisition of data, manuscript revision. All authors gave final approval for publication of the manuscript.

\section{References}

1. Lévy-Marchal C, Patterson CC, Green A (2001) Geographical variation of presentation at diagnosis of type I diabetes in children: the EURODIAB study. European and Diabetes. Diabetologia 44(Suppl 3):B75-B80
2. Sadauskaite-Kuehne V, Samuelsson U, Jasinskiene E et al (2002) Severity at onset of childhood type 1 diabetes in countries with high and low incidence of the condition. Diabetes Res Clin Pract $55: 247-254$

3. Hekkala A, Knip M, Veijola R (2007) Ketoacidosis at diagnosis of type 1 diabetes in children in northern Finland: temporal changes over 20 years. Diabetes Care 30:861-866

4. Rewers A, Klingensmith G, Davis C et al (2008) Presence of diabetic ketoacidosis at diagnosis of diabetes mellitus in youth: the Search for Diabetes in Youth Study. Pediatrics 121:e1258e1266

5. Samuelsson U, Stenhammar L (2005) Clinical characteristics at onset of type 1 diabetes in children diagnosed between 1977 and 2001 in the south-east region of Sweden. Diabetes Res Clin Pract 68:49-55

6. Edge JA, Hawkins MM, Winter DL, Dunger DB (2001) The risk and outcome of cerebral oedema developing during diabetic ketoacidosis. Arch Dis Child 85:16-22

7. Glaser N, Barnett P, McCaslin I et al (2001) Risk factors for cerebral edema in children with diabetic ketoacidosis. The Pediatric Emergency Medicine Collaborative Research Committee of the American Academy of Pediatrics. N Engl J Med 344:264-269

8. Gale EAM (2002) The rise of childhood type 1 diabetes in the 20th century. Diabetes 51:3353-3361

9. Patterson CC, Dahlquist GG, Gyürüs E, Green A, Soltész G (2009) Incidence trends for childhood type 1 diabetes in Europe during 1989-2003 and predicted new cases 2005-20: a multicentre prospective registration study. Lancet 373:2027-2033

10. Schober E, Rami B, Waldhoer T (2010) Diabetic ketoacidosis at diagnosis in Austrian children in 1989-2008: a population-based analysis. Diabetologia 53:1057-1061

11. Mallare JT, Cordice CC, Ryan BA, Carey DE, Kreitzer PM, Frank GR (2003) Identifying risk factors for the development of diabetic ketoacidosis in new onset type 1 diabetes mellitus. Clin Pediatr 42:591-597

12. Komulainen J, Kulmala P, Savola K et al (1999) Clinical, autoimmune, and genetic characteristics of very young children with type 1 diabetes. Childhood Diabetes in Finland (DiMe) Study Group. Diabetes Care 22:1950-1955

13. Pawłowicz M, Birkholz D, Niedźwiecki M, Balcerska A (2009) Difficulties or mistakes in diagnosing type 1 diabetes in children? Demographic factors influencing delayed diagnosis. Pediatr Diabetes 10:542-549

14. Karges B, Neu A, Hofer SE et al (2011) Frequency and influencing factors of ketoacidosis at diabetes onset in children and adolescents: a long-term study between 1995 and 2009. Klinische Pädiatrie 223:70-73

15. Neu A, Hofer SE, Karges B, Oeverink R, Rosenbauer J, Holl RW (2009) Ketoacidosis at diabetes onset is still frequent in children and adolescents: a multicenter analysis of 14,664 patients from 106 institutions. Diabetes Care 32:1647-1648

16. Bowden SA, Duck MM, Hoffman RP (2008) Young children $(<5 \mathrm{yr})$ and adolescents $(>12 \mathrm{yr})$ with type 1 diabetes mellitus have low rate of partial remission: diabetic ketoacidosis is an important risk factor. Pediatr Diabetes 9:197-201

17. Pinkey JH, Bingley PJ, Sawtell PA, Dunger DB, Gale EA (1994) Presentation and progress of childhood diabetes mellitus: a prospective population-based study. The Bart's-Oxford Study Group. Diabetologia 37:70-74

18. Craig ME, Hattersley A, Donaghue K (2006) ISPAD Clinical Practice Consensus Guidelines 2006-2007. Definition, epidemiology and classification. Pediatr Diabetes 7:343-351

19. Elding Larsson H, Vehik K, Bell R et al (2011) Reduced prevalence of diabetic ketoacidosis at diagnosis of type 1 diabetes in young children participating in longitudinal follow-up. Diabetes Care 34:2347-2352 
20. Vanelli M, Chiari G, Ghizzoni L, Costi G, Giacalone T, Chiarelli F (1999) Effectiveness of a prevention program for diabetic ketoacidosis in children. An 8-year study in schools and private practices. Diabetes Care 22:7-9

21. King BR, Howard NJ, Verge CF et al (2012) A diabetes awareness campaign prevents diabetic ketoacidosis in children at their initial presentation with type 1 diabetes. Pediatr Diabetes 13:647-651

22. Mortensen HB, Swift PGF, Holl RW et al (2010) Multinational study in children and adolescents with newly diagnosed type 1 diabetes: association of age, ketoacidosis, HLA status, and autoantibodies on residual beta-cell function and glycemic control 12 months after diagnosis. Pediatr Diabetes 11:218-226

23. Fernandez Castañer M, Montaña E, Camps I et al (1996) Ketoacidosis at diagnosis is predictive of lower residual beta-cell function and poor metabolic control in type 1 diabetes. Diabetes Metabol 22:349-355

24. Svensson J, Lyngaae-Jørgensen A, Carstensen B, Simonsen LB, Mortensen HB (2009) Long-term trends in the incidence of type 1 diabetes in Denmark: the seasonal variation changes over time. Pediatr Diabetes 10:248-254

25. World Health Organization (1999) Definition, Diagnosis and Classification of Diabetes Mellitus and its Complications. Part 1: Diagnosis and Classification of Diabetes Mellitus. WHO, Geneva

26. Svensson J, Marinelli K, Eising S (2007) Comparison of registration of data from the Danish Childhood Diabetes Register and The National Discharge Register. Ugeskr Laeger 169:122-125

27. Dunger DB, Sperling MA, Acerini CL et al (2004) ESPE/LWPES consensus statement on diabetic ketoacidosis in children and adolescents. Arch Dis Child 89:188-194
28. Mortensen HB, Hougaard P, Swift P et al (2009) New definition for the partial remission period in children and adolescents with type 1 diabetes. Diabetes Care 32:1384-1390

29. Rodacki M, Pereira JRD, Nabuco de Oliveira AM et al (2007) Ethnicity and young age influence the frequency of diabetic ketoacidosis at the onset of type 1 diabetes. Diabetes Res Clin Pract 78:259-262

30. Hanas R, Lindgren F, Lindblad B (2007) Diabetic ketoacidosis and cerebral oedema in Sweden: a 2-year paediatric population study. Diabet Med J Br Diabet Assoc 24:1080-1085

31. Hekkala A, Reunanen A, Koski M, Knip M, Veijola R (2010) Agerelated differences in the frequency of ketoacidosis at diagnosis of type 1 diabetes in children and adolescents. Diabetes Care 33:1500-1502

32. Quinn M, Fleischman A, Rosner B, Nigrin DJ, Wolfsdorf JI (2006) Characteristics at diagnosis of type 1 diabetes in children younger than 6 years. J Pediatr 148:366-371

33. Spencer J, Cooper H, Milton B (2010) Qualitative studies of type 1 diabetes in adolescence: a systematic literature review. Pediatr Diabetes 11:364-375

34. Salman H, Abanamy A, Ghassan B, Khalil M (1991) Childhood diabetes in Saudi Arabia. Diabet Med J Br Diabet Assoc 8:176178

35. Komulainen J, Knip M, Sabbah E et al (1998) Autoimmune and clinical characteristics of type I diabetes in children with different genetic risk loads defined by HLA-DQB1 alleles. Childhood Diabetes in Finland Study Group. Clin Sci (Lond) 94:263-269

36. The Diabetes Control, Complications Trial Research Group (1998) Effect of intensive therapy on residual beta-cell function in patients with type 1 diabetes in the diabetes control and complications trial. A randomized, controlled trial. Ann Intern Med 128:517-523 